3

\title{
Transforming Self-Narratives in Psychotherapy: Looking at Different Forms of Ambivalence in the Change Process
}

\author{
Carla Alexandra Castro Cunha, Miguel M. Gonçalves \\ and Jaan Valsiner
}

In recent decades, several psychologists have emphasized the central role that narratives play in human life (Sarbin, 1986; Bruner, 1990; McAdams, 1993; Hermans and Hermans-Jansen, 1995). If, as Bakthin (1984) argued, 'to be is to communicate' (p. 187), narratives are as important to the self as they are for others with whom we relate: One (re)constructs and (re)presents oneself through narrating, being influenced by the dialogical parties we encounter in life. Therefore, a fundamental challenge for psychological science is to find out how the self is constituted and transformed through narratives. Namely, what kinds of narratives empower the self with adaptive resources fostering selfdevelopment, and what other kinds block transformation, increasing vulnerability?

According to narrative and dialogical perspectives, some selfnarratives may become dysfunctional and constrain personal adaptation if they lack differentiation, flexibility or become too redundant. For example, some self-narratives may express a dominant voice (or a coalition of voices) that silences alternatives (Hermans and Kempen, 1993) or become so saturated on problems that the disempowered self surrenders in helplessness (White and Epston, 1990). Other selfnarratives may show a redundancy of themes or contents around hurtful experiences and characters (Hermans and Hermans-Jansen, 1995), indicating a bias towards negative events on autobiographical recall and perpetuating a negative view upon oneself (Gonçalves and Machado, 1999). Other narratives may be too disorganized and 


\section{PROOF}

unspecific, failing to articulate a coherent sense of personal agency (Botella et al., 2004; Boritz et al., 2008). These examples illustrate some of the features that frequently characterize problematic narratives exhibited by clients in the beginning of psychotherapy, leading them to seek professional help (see Dimaggio, 2003, for a comprehensive discussion).

Our research program has tried to depict how the elaboration of novelties allows the transformation of problematic self-narratives in the psychotherapy context (Gonçalves et al., 2009; Gonçalves et al., 2010). For that we created the Innovative Moments Coding System (Gonçalves et al., in press) which allows tracking novelties that emerge in the therapeutic conversation. If we consider the problematic narrative presented by a client as a rule, these novelties are all the experiences that are taken as exceptions that contradict it. We call these experiences innovative moments (hereafter IMs; Gonçalves, Santos et al., 2010) to refer to the actions, feelings, intentions and thoughts that express defiance towards the dominance of the problematic narrative. This is inspired by White and Epston's (1990) notion of 'unique outcomes', that is, experiences outside the influence of the problem-saturated stories that clients bring to therapy.

To summarize this chapter's main assumptions - and adopting the theatre analogy, useful in the dialogical self perspective (Hermans et al., 1992; Hermans, 2001) - we can conceive the problematic selfnarrative as the expression of a voice or coalition of voices that monopolizes the floor of the dialogical self and restrains the expression of alternative voices. Consequently, the problematic voice(s) assume the narrator's position, controlling which self-narratives become possible to express, without relenting its power to non-dominant voices. In contrast, IMs represent the narrative expression of alternative voices that in time take the floor, being heard and developed in psychotherapy, and contest the dominant voices that saturate problematic self-narratives. Every time a meaningful change is noticed in the therapeutic dialogue, alternative voices (new or previously dominated) can come to the foreground and start to develop potential new narrators and more flexible self-narratives.

In the following, we elaborate on different instances of ambivalence between problematic and innovative voices manifested by clients during the change process. We also discuss the potential of developing and expanding the activity of a meta-position in the self as a way to deal with ambivalence and to strengthen the path towards a new self-narrative. 


\section{PROOF}

Transforming Self-Narratives in Psychotherapy

\section{Narrative change in psychotherapy: Elaborating the role of innovative moments}

The Innovative Moments Coding System distinguishes five types of IMs: action, reflection, protest, reconceptualization and performing change IMs (see Table 3.1). Although some of our studies look at nontherapeutic change in everyday life (Meira, 2009), our main focus has been on brief psychotherapy process (typically of 12 to 20 sessions per case; e.g., Matos et al., 2009; Mendes et al., in press; Gonçalves et al., in press; Santos et al., 2009).

The findings led to setting up a model of IMs' development and progression, typically evidenced in successful therapy cases. According to this model (Gonçalves et al., 2009), the initial signs of narrative change that appear in the first half of treatment (initial sessions) assume the form of action, reflection and protest IMs. More specifically, clients may start by talking about new actions, activities and behaviours that were experimented in their daily life and that challenge the usual expectation of acting according to the problem's prescriptions ('action IMs'). Usually the elaboration upon these actions feeds new thoughts, feelings, intentions and understandings about the problem and its supporters that were not grasped before ('reflection IMs'). Sometimes, the person even enacts in the sessions a more explicit attitudinal refusal or overt critiques against the problem or problem supporters (e.g., certain people or groups allowing the problem, parts of the self endorsing it or giving in to it) in the form of 'protest IMs'. This type of IM facilitates disengagement between the self and the problem, which reinforces more changes. Moreover, these three types of IMs feed each other in the beginning of treatment, increasing its duration, as the person pays more attention to these new experiences and feels more motivated to defy the problematic narrative, through the enactment and articulation of changes.

An important marker in the change process is the emergence and development of 'reconceptualization IMs' from the middle of therapy until the end, becoming the dominant type of IM. This is a distinctive feature of successful cases, since reconceptualization IMs are usually absent in unsuccessful cases (to be elaborated in the following). This is understandable when considering the defining features of this type of IM: The person narrates a contrast between self in the past and self in the present - thus, the client is aware of selftransformation - and also describes the processes that lead to this transition, adopting a meta-perspective about him-/herself. Various 


\section{PROOF}

Table 3.1 Types of Innovative Moments with examples from depressed clients

\begin{tabular}{|c|c|}
\hline Types of Innovative Moments (IMs) & $\begin{array}{l}\text { Examples (Problematic } \\
\text { narrative: Depression) }\end{array}$ \\
\hline $\begin{array}{l}\text { Action IMs } \\
\text { Action IMs refer to events or episodes when the person } \\
\text { acted in a way that is contrary to the problematic } \\
\text { self-narrative. }\end{array}$ & $\begin{array}{l}\text { C: Yesterday, I went to the } \\
\text { cinema for the first time in } \\
\text { months! }\end{array}$ \\
\hline $\begin{array}{l}\text { Reflection IMs } \\
\text { Reflection IMs refer to new understandings or thoughts } \\
\text { that undermine the dominance of the problematic } \\
\text { self-narrative. They can involve a cognitive challenge } \\
\text { to the problem or cultural norms and practices that } \\
\text { sustain it, or new insights and understandings about the } \\
\text { problem or problem supporters. These IMs frequently } \\
\text { can also assume the form of new perspectives or } \\
\text { insights upon the self while relating to the problem, } \\
\text { which contradict the problematic self-narrative. }\end{array}$ & $\begin{array}{l}\text { C: I realise that what I was } \\
\text { doing was just, not humanly } \\
\text { possible because I was } \\
\text { pushing myself and I never } \\
\text { allowed myself any free time, } \\
\text { uh, to myself... and it's more } \\
\text { natural and more healthy } \\
\text { to let some of these extra } \\
\text { activities go... }\end{array}$ \\
\hline
\end{tabular}

\section{Protest IMs}

Protest IMs involve moments of critique, confrontation or antagonism towards the problem and its

C: I am an adult and I am responsible for my life, specifications and implications or people that support it. and, I want to acknowledge They can be directed at others or at the self. Oppositions these feelings and I'm going of this sort can either take the form of actions (achieved to let them out! I want to or planned), thoughts or emotions, but necessarily imply experience life, I want to an active form of resistance, repositioning the client in a more proactive confrontation to the problem (which does not happen in the previous action and reflection IMs). Thus, this type of IM entails two positions in the self: one that supports the problematic self-narrative and another that challenges it. These IMs are coded when the second position acquires more power than the first.

\section{Re-Conceptualisation IMs}

Re-conceptualisation IMs always involve two dimensions: (a) a description of the shift between two positions (past and present) and (b) the transformation process that underlies this shift. In this type of IM there is the recognition of a contrast between the past and the present in terms of change, and also the ability to describe the processes that lead to that transformation. In other words, not only is the client capable of noticing something new, but also capable of recognising oneself as different when compared to the past due to a transformation process that happened in between. grow and it feels good to be
in charge of my own life. I
am not going to put up with this anymore!

C: You know... when I was there at the museum, I thought to myself: you really are different.... A year ago you wouldn't be able to go to the supermarket! Ever since I started going out, I started feeling less depressed...it is also related to our conversations and changing jobs... T: How did you have this idea of going to the museum? C: I called my dad and told him: we're going out today! T: This is new, isn't it? C: Yes, it's like I tell you...I sense that I'm different...

Continued 


\section{PROOF}

Transforming Self-Narratives in Psychotherapy

Table 3.1 Continued

\begin{tabular}{ll}
\hline Types of Innovative Moments (IMs) & $\begin{array}{l}\text { Examples (Problematic } \\
\text { narrative: Depression) }\end{array}$ \\
\hline $\begin{array}{l}\text { Performing Change IMs } \\
\text { Performing change IMs refer to new aims, projects, }\end{array}$ & $\begin{array}{l}\text { T: You seem to have so } \\
\text { activities or experiences (anticipated or already }\end{array}$ \\
$\begin{array}{l}\text { many projects for the } \\
\text { acted) that become possible because of the }\end{array}$ & $\begin{array}{l}\text { C: Yes, you're right. I want } \\
\text { acquired changes. Clients may apply new abilities }\end{array}$ \\
and resources to daily life or retrieve old plans or & to do all the things that \\
intentions postponed due to the dominance of the & were impossible for me to \\
problem. & $\begin{array}{l}\text { do while I was dominated } \\
\text { by depression. I want to }\end{array}$ \\
& $\begin{array}{l}\text { work again and to have } \\
\text { the time to enjoy my life } \\
\text { with my children. I want } \\
\text { to have friends again. The } \\
\text { loss of all the friendships } \\
\text { of the past is something } \\
\text { that still hurts me really } \\
\text { deeply. I want to have } \\
\text { friends again, to have } \\
\text { people to talk to, to share } \\
\text { experiences and to feel } \\
\text { the complicity in my life } \\
\text { again. }\end{array}$ \\
\hline
\end{tabular}

studies, with different therapy samples and diverse client problems, evidence the emergence of reconceptualization IMs as an important turning point in the change process (Gonçalves et al., 2009; Gonçalves et al., 2010). This turning point appears to be characteristic of changes achieved through psychotherapy, a context of which

${ }_{A Q 1}$ an important defining feature is the dialogue with an interlocutor particularly interested in discussing changes and fostering development. The emergence of reconceptualization IMs feeds new action, reflection and protest IMs that act as signs that further transformations are under way.

Finally, performing change IMs emerge after reconceptualization, emphasizing the projection of changes into the future. These IMs also represent further signs that change is being consolidated and rehearsed, this time in the form of new projects, plans and aims that become possible only because the client became a changed person, with new resources and skills. This global model is depicted in Figure 3.1. 


\section{PROOF}
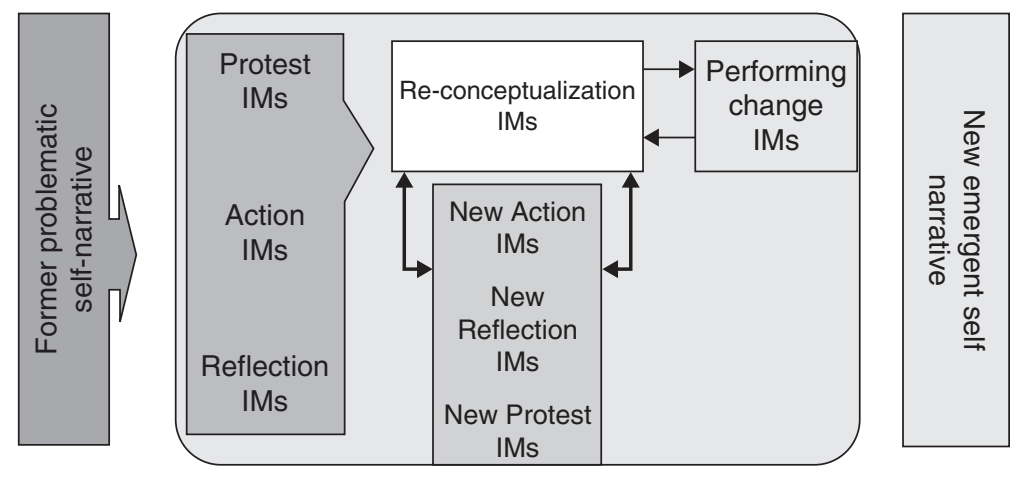

Therapy evolution

Figure 3.1 A heuristic model of change and Innovative Moments evolution in successful therapy

\section{The centrality of reconceptualization IMs in promoting change}

Looking at reconceptualization IMs more deeply, we can distinguish them in terms of content, dialogical process and narrative structure (Gonçalves and Salgado, in preparation).

At the level of content, these IMs present two defining characteristics (Gonçalves and Salgado, forthcoming): (a) contrast in the self (between past and present) and (b) access to the change process, articulated through the viewpoint of a meta-perspective of the self. These characteristics serve different psychological purposes in the developing self. First, the contrast expressed in these narratives implies the recognition of an identity rupture - or, at least, a discontinuity in the self (Cunha et al., forthcoming; Zittoun, 2007). Zittoun argues that these perceived ruptures, interruptions or discontinuities can lead to questioning one's personal identity (we realize we are no longer the same as before), and trigger efforts to understand what has happened and reconstitute one's sense of identity, consequently restoring self-continuity. Reconceptualization IMs are attempts to restore self-continuity through disengaging with a previous self-narrative and identifying with a new self-version (Cunha et al., forthcoming; see Figure 3.2).

Such discontinuity can be unsettling and ambivalent, as the person struggles to achieve new self-familiarity (Cunha et al., forthcoming; Zittoun, 2007). Several trials of reconceptualization IMs might be 


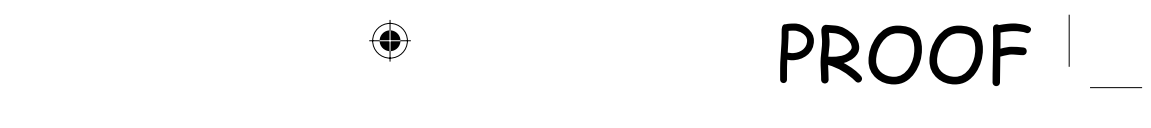

Transforming Self-Narratives in Psychotherapy

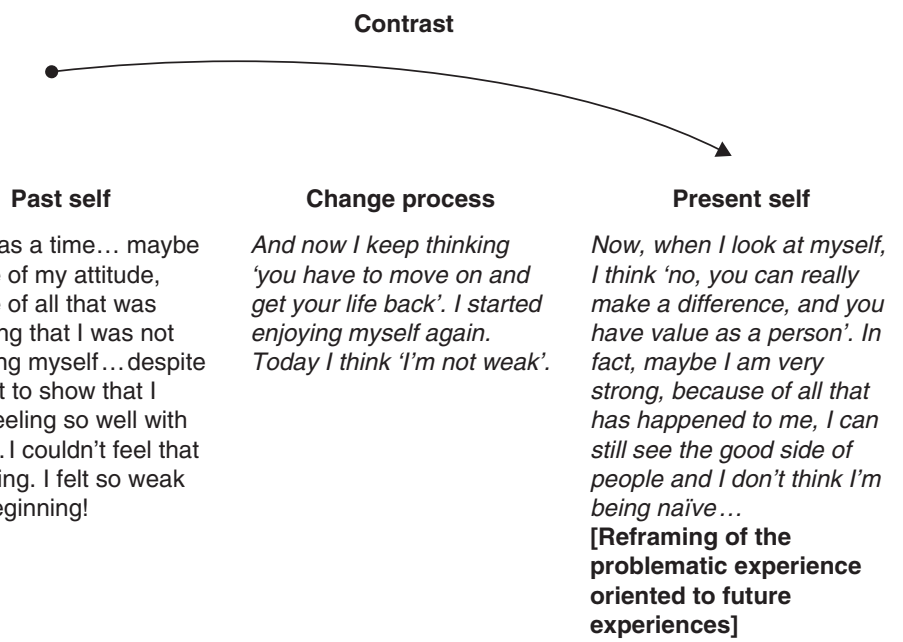

Figure 3.2 An example of a re-conceptualization Innovative Moment

needed to develop a new self-authorship and consolidate a new selfnarrative (see case study in Cunha et al., forthcoming).

Another aspect contributing to the importance of reconceptualization IMs is the enablement of a meta-perspective, or meta-position, in the self. Several authors argue that the potentialities of this metaperspective view are innumerable for change in psychotherapy (Hermans, 2001, 2003: Gonçalves and Ribeiro, in press). Indeed, this distinguishes reconceptualization IMs in terms of dialogical process from other IM types. That is, we have here three positions: the self in the past (old voice), the self in the present (new voice), and a position detached from both and articulating both.

Finally, reconceptualization IMs are distinguishable from novelties like action, reflection and protest by their specific narrative structure. As mentioned, the other IMs emerge early in therapy and are usually more discrete and episodic. Through the emergence of reconceptualization, these can become integrated in a more complex narrative that provides a new future orientation, a new sense of agency and authorship grounded in a more positive emotional way of being. Furthermore, it is not rare to notice a positive reframing of problematic or painful experiences (Stiles, 2001; Honos-Webb et al., 2003) within reconceptualization, as these experiences become integrated more constructively, sometimes regarded as learning events or 


\section{PROOF}

helpful resources in the adaptation to future challenges (Santos and Gonçalves, 2009).

\section{Mutual in-feeding and ambivalence in the narrative flow}

How do people become entrapped in problematic self-narratives? This concern with therapeutic failure is present in almost every model of psychotherapy, and traditionally is addressed in terms of resistance (Arkowitz, 2002). However, there is no consensus across models, as each highlights different sets of dimensions that resistance entails. For example, clients may be reluctant to engage in therapeutic tasks, prescriptions and assignments (behavioural resistance), evade certain conversation topics, explore thoughts and feelings or manifest difficulties in comprehending patterns of problematic experiences and relationships (cognitive and/or affective resistance) (Arkowitz, 2002). Some authors have recently applied an integrative approach (Engle and Holiman, 2002; Messer, 2002; Engle and Arkowitz, 2008). We consider resistance as the client's multiple manifestations of core ambivalence towards change.

The notion of mutual in-feeding addresses that ambivalence towards change from the perspective of the IM. This concept, derived from Valsiner (2002), refers to the immediate return to a problematic narrative after the expression of an IM (Gonçalves et al., 2009; Santos et al., 2010). In our view, this phenomenon is one of the paths that may lead to a problematic self-stability (or resistance) and ultimately to therapeutic failure. More specifically, mutual in-feeding maintains a dynamic stability between a position and its counter-position (problematic voice and innovative voice), with each feeding the other. This creates a rapid oscillation between opposing positions that, despite being dynamic and interchangeable, is not developmental: 'It becomes developmental only if the relation between parts can permit new parts - and relations between parts - to emerge' (Valsiner, 2002, p. 260). Therefore, this oscillation keeps the person stuck in the movement between innovation and the problematic narrative (Gonçalves, Ribeiro, Conde et al., in press). An example of mutual in-feeding could be: 'I would like to be able to drive again [Reflection IM, an innovative voice in a driving phobia] but I can't bear the fear [return to the problematic narrative].'

Empirically, such return to the problem may be signalled by return-tothe-problem markers (RPMs; Gonçalves, Ribeiro, Conde et al., in press), which are utterances appearing immediately after and denying an IM (such as but-sentences). Studies by Gonçalves, Ribeiro, Conde et al. (in press) show that RPMs are more likely to follow IMs in unsuccessful 


\section{PROOF}

Transforming Self-Narratives in Psychotherapy

51

cases than in successful ones, and these differences are visible since the beginning of therapy. Moreover, RPMs frequently followed certain IMs types - such as reflection and protest - which seem more vulnerable to mutual in-feeding. RPMs were less likely to follow reconceptualization and performing change IMs, probably because these are markers of sustained change.

The concept of mutual in-feeding conceptualizes resistance as a way to maintain a status quo centred on the problem. Engle and Arkowitz $(2006,2008)$ have similarly explored clients' ambivalence, referring to these instances as resistant ambivalence. Like mutual in-feeding, resistant ambivalence highlights a conflict between changing and remaining the same (see also Arkowitz, 2002; Engle and Holiman, 2002). Ambivalence may appear after the motivated client has already experienced some changes, though its timing in the process may be a little surprising. Nevertheless, these instances of ambivalence should not be looked at negatively as enemies of change (Messer, 2002) but instead as forms of self-protection (Engle and Holiman, 2002). Engle and Arkowitz (2006, 2008) delineate in detail several reasons for not changing. For our purposes, we simplify their elaboration. Resistant ambivalence (or mutual in-feeding) may be evoked by:

(a) fear and anxiety experienced in the process of changing from something familiar into something unknown;

(b) conscious or unconscious faulty beliefs about oneself and change;

(c) a reactance to the pressure to change that others may apply (feeling that one's personal freedom is restrained);

(d) secondary functions or gains produced by the problematic behaviour (such as others' attention and care); and

(e) fear of becoming overwhelmed by negative emotions evoked by problematic experiences.

\section{Enabling a meta-position to deal with ambivalence}

Recently, it has been emphasized that psychotherapeutic change is the result of developing the client's self-observation skills (Dimaggio et al., 2003; Dimmagio, 2006). Dialogical Self Theory associates such skills with the activity of a meta-position (Hermans and Kempen, 1993; Hermans, 2001, 2003), sometimes referred to as 'observer position' (Leiman and Stiles, 2001) or 'meta-perspective' (Gonçalves et al., 2009). The emergence and expansion of such a position is considered as an important step for promoting healthier dialogues and narratives within the self. 


\section{PROOF}

Hermans and Kempen (1993) define a meta-position as 'a perspective from which the client phrases the linkages between several significant positions in a self-reflective way' (p. 133). It provides an overarching view upon different aspects of the self, thus taking a step back from the problematic experience and fostering self-observation: 'A well-developed metaposition... enables clients to separate themselves from the ongoing stream of experiences and to place themselves as authors, considering themselves as actors in specific situations' (Hermans, 2003, p. 122-3). This process creates psychological distancing: 'The individual psychologically moves away from the object of perception, such that the object becomes distinct from the self' (Abbey, 2004, p. 32). Acquiring a perspective disengaged from the problematic voice also enables the recognition of one's ambivalences, tensions and conflicts. Therapists' efforts to acknowledge and explore difficulties may provide an opportunity for the emergence of something new. As clients are freer to reflect upon the origin and adequacy of voices resisting change, they may adopt a different attitude to change (Cunha et al., forthcoming). Clients could also understand which valuable needs the voices of ambivalence communicate to the self, welcoming them into dialogue (Greenberg et al., 1993; Engle and Holiman, 2002). Thus, ambivalences can be converted into something productive for the therapeutic process.

Moreover, Hermans (2001) argues that a meta-position can evaluate alternative positions that might have remained hidden or underdeveloped in the shadow of the problematic self-narrative (like shadow voices in the self; Gonçalves et al., 2009). This movement of understanding the relation and contrast between positions and how they are integrated (or cast aside) in the dialogical self provides further opportunities to discover or promote relevant linkages among alternative positions and personal history (Hermans, 2001, 2003). We can draw a connection with the functions of reconceptualization mentioned previously, in particular the efforts to restore continuity and unity in the self after the disengagement with the problematic position. In addition, this type of meta-level reflexivity may facilitate the directionality of change into the future, inaugurating a new authorship where new self-positions and possibilities may be construed, including the renewal of self-narratives (Cunha et al., forthcoming; Hermans, 2001; Gonçalves et al., 2009).

\section{Case examples}

We present three successful cases of clients admitted to brief emotionfocused therapy for depression under the York I Depression Project 


\section{PROOF}

Transforming Self-Narratives in Psychotherapy

(Greenberg and Watson, 1998). Several authors present case studies of these clients (Cunha et al., forthcoming; Honos-Webb et al., 1998; Honos-Webb et al., 1999; Leiman and Stiles, 2001; Honos-Webb et al., 2003; Gonçalves et al., 2010). Below, we look only at their first reconceptualization IMs (expanded in Mendes et al., in press). The selected excerpts represent moments when the self re-evaluates itself and deals with different forms of ambivalence. We have edited these excerpts to eliminate repetitions and speech hesitations, due to space constraints. In all the excerpts, IMs are signalled in bold.

\section{Case 1}

'Sarah' was a 35-year-old German immigrant in Canada (expanded in Cunha et al., forthcoming; Honos-Webb et al. 2003). She attended 18 therapy sessions. As a part-time college student, recently divorced, she searched for help with her depressive symptoms and increasing sense of isolation. Her main complaints regarded her difficulties of being assertive and of clearly realizing her feelings, and frequently doubting herself. She focused too much on pleasing others and frequently dismissed her own needs.

In the extract below, taken from Session 7, Sarah begins by expressing how she has already achieved some changes in interpersonal situations. She presents herself as more assertive, which triggers a reconceptualization IM. She highlights the contrast between present and past. She also elaborates upon what is different even though some problems remain (I still find it hard to get going in the mornings). Her therapist acknowledges these difficulties but leads Sarah to explore innovation. This is performed afterwards in several turns of the conversation. Sarah reports changes, denotes some remnants of the problem, but proceeds to expand the elaboration upon innovation; the therapist acknowledges difficulties, but proceeds to pointing out and clarifying what is different:

AQ2 Therapist: So how do you feel?

Sarah: Well I'm not too bad, I don't try to sweep away things that much anymore. [Meta-position emerges, observing the self.] That's I guess one major change which I really like, even so I still find it hard to get going in the mornings [remnants of the problematic narrative] but...

Therapist: It's hard to get going, but what did you say, you don't? [Therapist explores innovation.]

Sarah: Like before well it would get to the point where I would get up and do really basic things and then take 


\section{PROOF}

a lot of breaks and rest during the day. And that has not really disappeared, but it's simply because I'm so busy, I don't have the chance. And I guess the sudden change - well, it was kind of gradual, I suppose - it leaves me pretty tired for things. But it's kind of a nice change of things.

Therapist: So it's hard to get started but once you're into it, it keeps you moving through the day.

Sarah: $\quad$ Yeah and I guess the thing really is that, if I'm on my own, I really let it go, let myself go. So I'm trying to keep myself busy and involved, especially with other people. If I have to do something on my own at home, it's just really difficult to get a move on things and well ... I don't know, it's just how it works right now.

Therapist: So it sounds like you're trying to give yourself some structure that helps you. (Sarah: Mm-hmm) You know you have to be at certain places at certain times. [Therapist discriminates what is different, helping the client to become more aware and acquire control upon the changes.]

Sarah: $\quad$ Mm-hm, yeah, that kind of puts that certain amount of - I don't know, pressure is maybe not the right word - but I'm aware of what's going on and what's the best way to deal with it. (Therapist: Mm-hm.) So that really helps and also I'm kind of getting the hang of it, like what makes me uncomfortable when I'm with other people and really try my best, as soon as I notice it [discomfort in interpersonal situations] to deal with it. To let them know that 'No, this is not acceptable to me' or 'No, I can't deal with it for whatever reason' but it's just too much and it works really well (laughs).

Therapist: So it sounds like two things are different: One is that you're able to notice it quicker (Sarah: Mm-hm.) or you are able to make sense of something making you uncomfortable, and then you come out and set your limits and do something about it.

Sarah: Mm-hm, even though this creates (interrupts with a small pause, letting the therapist infer about some negative feelings) at the time, I know 'Ok, right now this is it. I have to do or say something, otherwise it's going to happen again [...] So I get kind of tense about it but then I say or do whatever it is. And it's 


\section{PROOF}

Transforming Self-Narratives in Psychotherapy

55

just, I can't believe how difficult I find it to do this, like to be assertive (Therapist: Mmm.) about things. [Reconceptualization IM - Ambivalence expressed by a metaposition in the self, reflecting upon the self as changing.]

Therapist: So it feels like it shouldn't be so difficult.

Sarah: Yeah because I feel kind of guilty about it. (Therapist: Mm-hm.) Um, for somewhere around a day almost [questioning, doubting herself]. Was I entitled really to do this? You know, did I hurt the other person? [Mutual in-feedingReturn to the problematic narrative, as self-doubt appears.]

Therapist: Mm-hm.

Sarah: It's always like I'm more concerned about what I do to the other person then saying 'Well, this is me, I have to look at myself first, other people are doing it and I have to let them know where the limit is, that they have to look for a different approach or that they definitely overstepped it'. [Meta-position, observing the self.]

Therapist: It sounds like at the time you're able to do that, to set your limits and yet you're left with this disconcerting feeling like 'Maybe I shouldn't have, maybe I hurt them', that kind of thing? [Therapist acknowledges difficulties and mirrors the ambivalence to Sarah.]

Sarah: Yeah, but then the next time when I encounter them I notice in their behaviour that they know and acknowledge it. [Meta-position differentiating.] I put something forward and they just have to live with it, to acknowledge it. I kind of staked out the border or indicated the limits, how far they can go. I mean, there are a few things happening last week and this week and, now when I think about it, 'My gosh, I'm just so glad I did it!' And I guess it's a start.

Therapist: So, you're saying, the guilty feeling in a way doesn't last too long. In the end, when it's all said and done, you're happy. [Reflection IM.]

It is then that a more pronounced marker of ambivalence to change emerges in the midst of reconceptualization: Although adopting a meta-reflective stance and observing herself as a changed actor, Sarah discloses to her therapist how she never thought that acting in the desired, changed way, would be so difficult (I can't believe how difficult I find it to do this, like to be assertive). The therapist is responsive to her 


\section{PROOF}

difficulties and proceeds to explore them (it feels like it shouldn't be so difficult). Now, the ambivalence fully differentiates into the process of mutual in-feeding, circumventing reconceptualization: Sarah returns to the problematic narrative, manifesting guiltiness and self-doubts (I feel kind of guilty about it).

Yet, this step back into the usual problematic functioning is not long, as the client's meta-position evolves to noticing how others react to a changing Sarah and moves along to an assertion of her own needs, this time, in the form of a reflection IM. And despite the fact that Sarah's therapist keeps acknowledging her difficulties and mirroring the ambivalence to her (yet you're left with this disconcerting feeling like 'Maybe I shouldn't have'), Sarah is already in motion in a reinvigorated emphasis on change (I'm just so glad I did it! And I guess it's a start) that motivates further innovation in the process.

\section{Case 2}

'Jan' was a 42-year-old white female, working as a sales person (expanded in Honos-Webb et al. 1999; Gonçalves and Ribeiro, in press). She attended 16 therapy sessions, and was considered clinically depressed. The most important symptoms to her were lack of motivation at work, and some psychosomatic complaints such as hives (urticaria) and difficulties swallowing. During therapy, Jan understood that her symptoms were frequently signs of the burden she placed on herself in work and family environments, as she took extra responsibility for taking care of everyone and catered too much to others' needs.

In the next extract, taken from Session 4, Jan discloses that her hives came back after a brief remission in the first weeks of psychotherapy. By this time, Jan had already made some progress towards change and the symptoms return troubles her:

Jan: $\quad$ My hives came back this week again - I thought they were sort of gone but I had two, three days where, you know, they were back. I still have them but that two, three days were worse than before. So that caused, you know, sort of a little bit of worry. [Ambivalence starts to emerge implicitly in the form of a negative feeling.]

Therapist: Mm, about?

Jan: That they're going to come back as bad as they were before, and I'm not getting anywhere. [Ambivalence in the form of fear of failing to change - Problematic narrative.]

Therapist: Mm-hm, so the hives kind of tell you that maybe... 


\section{PROOF}

Transforming Self-Narratives in Psychotherapy

Jan: I think that's a trigger point. [Meta-position, observing the self.] (Therapist: Yeah.) I think I've accepted it that the hives are something that subconsciously my body is telling me - that I have to do something - um, make some changes (Therapist: Mm-hm.) you know, whichever they are.

Therapist: That's sending you a message.

Jan: $\quad$ Mm-hm. I just have to listen to it and not ignore it like I have in the past.

Therapist: Mm-hm. So it's kind of an important sign that something's going on. [Therapist reinforces Jan's insight.]

Jan: Yeah, I think that's the only thing, really the hives are the only thing that's really triggering it for me, because it's visual.

Therapist: Mm-hm, so you can really see that something's going on.

Jan: $\quad$ Mm-hm. I can't ignore it as much as (Therapist: Mm-hm.) you know, I can ignore a headache or a pain in my neck or something like that. [Reconceptualization IM]

As Jan talks about the hives, she expresses how these symptoms triggered some negative feelings again (worry) and ambivalence towards change starts to emerge implicitly. This ambivalence could have evolved to a case of mutual in-feeding but, in this case, Jan's concerns are more focused on a fear of failing to change despite her efforts and therapeutic help. Her therapist, acknowledging these difficulties, leads Jan to explore them further. And this is where the meta-position appears, and Jan elaborates a reconceptualization IM. Through this meta-position, Jan discovered something new about her problems (I think that's a trigger point) which allows a reframing of the symptoms: They are, after all, bodily signs that indicate a need to persevere and keep changing (I just have to listen to it and not ignore it like I have in the past), instead of a marker of failure. This interesting movement towards constructing the symptom as an important, positive sign is the result of an intersubjective process between client and therapist (initiated in earlier sessions), whose interventions reinforce and validate Jan's view (So it's kind of an important sign that something's going on).

Case 3

'Lisa' was a 27-year-old woman with an Italian background, married and with two children (expanded in Gonçalves, Mendes et al., in press; 


\section{PROOF}

Honos-Webb et al., 1998; Leiman and Stiles, 2001). She attended 15 therapy sessions. Lisa was considered clinically depressed, and her main complaints regarded sadness, resentment and guilt towards her husband and his gambling problem.

Lisa presents reconceptualization IMs from Session 1, as can be seen in the following. Here she explores her difficulties with her husband and children. The therapist tries to explore her emotional experiences in the marriage. This triggers a meta-position, as Lisa starts observing herself in her marital relationship (I feel like I'm the provider; There's no way of escaping). The therapist keeps helping Lisa to explore emotions associated with this relationship and, as she further observes herself, the first reconceptualization IM appears. From this point on, and with the therapist's help, it is clear that Lisa wants to disengage from her husband's problems and to focus more on herself, in contrast with what she used to do.

Therapist: And yet, it's still there, like somehow there's this feeling of ... [...] Can you talk about that a bit, just what it's like?

Lisa: Um, [Meta-position emerges, observing the self] I feel like I'm the provider, I'm there [in the marriage] for only that reason. (Therapist: Uh-huh.) Not so much that, you know, he [husband] wants to be with me, it's more that the kids are here and this is the way it's got to be and (Therapist: Uh-huh.) and that's, there's no way of escaping that $[. .$.

Therapist: So you start almost feeling helpless.

Lisa: That's right, I'm helpless about it, I can't do anything.

Therapist: Feels like there's just no way out [...] Because you still end up feeling hurt inside

Lisa: $\quad$ Yeah, the feelings are very much there even though I understand the disease [the gambling habit] and the character in him (Therapist: Yeah.) and I believe that he can be helped but he doesn't see it or he doesn't want it. And I've stopped changing him, I don't want to change him anymore, because you know I'm just looking at my own problems.

Therapist: Uh huh, so rather than try to control his behaviour, it's more like...

Lisa: Right, I don't do that anymore, I don't do that as much as I used to. 


\section{PROOF}

Transforming Self-Narratives in Psychotherapy

Therapist: You just focus on yourself and what you feel.

Lisa: $\quad$ Yeah, myself and what's happening at that moment. (Therapist: Mm-hm.) [Reconceptualization IM]

Lisa: When he says I'm going out or like last Sunday [describing how her husband had arrived late to a scheduled activity with the children and then she questioned him about that ] he said 'Oh, I was having a card game' and that just brings the feelings back, like you know, your family and kids come first!

Therapist: Mmm, so there's almost a feeling of resentment.

Lisa: $\quad$ Yeah, it's very strong, and I don't cut him up or anything, I never have.

Therapist: Yeah, you don't want to start yelling at him [...]. So I guess it just kind of feels like, even though there's this boiling kind of feeling inside 'I'm not going to tell him because (Lisa: Yeah) it's not going to do any good, it's not my responsibility anymore' [...]. So it sounds like you've gone and given up.

Lisa: $\quad$ Yeah, I do at this point.

Therapist: He's not going to change.

Lisa: No, I don't see it. Um, I don't know if I should be out there trying harder but I think I've given up. [Reflection IM - Ambivalence appears in the form of selfdoubt] (Therapist: Uh-huh) In that sense, I've kind of let God take over.

Therapist: Uh-huh, so there's a feeling of 'I gave up' and somehow there's sadness that comes to mind. (Lisa crying: Mm-hm.) Sort of as if you've lost something, I'm not sure.

Lisa: Yeah, I don't know what, but failure comes up to me. [Mutual in-feeding - Remnants of the problematic narrative]

Therapist: Uh-huh, it feels like you should have been able to.

Lisa: $\quad$ Yeah, something doesn't connect.

Therapist: Um, like you're not connecting with him, you're not getting through to him. Um, it's like trying to get close to a brick wall.

Lisa: Yeah, and I just don't want to get too close because (crying), I guess I don't want to be hurt more. (Therapist: Uh-huh.) Maybe that's why I've given up. [Reconceptualization IM] 


\section{PROOF}

Nevertheless, when Lisa talks about when her husband was late to something he had planned with their children, we see that rage and resentment towards her husband are still very much present in their daily life. The therapist introduces the notion of giving up old patterns, while trying to specify what has been changed in the way the couple interact (So it sounds like you've gone and given up). Here Lisa starts expressing some ambivalence. She begins by doubting her decision to distance herself from her husband's problems (I don't know if I should be out there trying harder), but immediately repositions herself, refusing responsibility (I've kind of let God take over). The therapist opts not to pursue this distancing movement, but explores further the ambivalence, looking for negative emotions. This activates mutual in-feeding, as traces of the problematic narrative emerge (failure for not being able to change her husband) in the form of a self-critical voice. Through this, we notice that Lisa is still very linked to the usual functioning of the relationship. But then the therapist introduces a powerful metaphor (it's like trying to get close to a brick wall) that reactivates Lisa's meta-position, potentiating another reconceptualization IM and a new insight about the problem (I just don't want to get too close because I don't want to be hurt more.).

\section{Synthesis}

As the three vignettes show, ambivalence is a common companion of the therapeutic process as clients readjust their own identity trying to accommodate recent changes. Despite this commonality, we believe that these three excerpts present different types of ambivalence, emerging at different moments of the change process and playing different roles in it.

In Sarah's case, the first reconceptualization IM appeared in Session 7; that is, in the middle of the psychotherapy process. The client initiated the therapeutic dialogue in this session by presenting herself as a changed person (i.e., more assertive). Despite her acknowledgement of some difficulties, there was a perceived rupture in the self, created by the identification with a new way of behaving. Along the elaboration of this innovative way of acting and being, Sarah's therapist intervened by validating the changes and by helping Sarah to understand how these have been set in motion. In her case, ambivalence emerged at the end of reconceptualization, as she adopted a meta-position and started reflecting upon how she felt during and after the performance of the changes. Thus, we believe that the type of ambivalence exhibited by this client was expressed by a meta-position as a reaction to some unexpected difficulties concerning the enactment of changes. The ambivalence 


\section{PROOF}

Transforming Self-Narratives in Psychotherapy

expressed by this meta-perspective was seen as a cue by her therapist who decided to explore these difficulties, instead of pursuing the elaboration around changes, as she did before. The acknowledgement of difficulties lead, then, to a full return to the problem - the process of mutual in-feeding - as the client disclosed feeling guilty to act assertively and doubting her right to change in her interpersonal relationships. Yet, as soon as Sarah revisited the problematic position, she immediately repositioned herself again as changed, initiating a reflection IM, where she reaffirmed her right to express herself and other people's duty to acknowledge her views. Therefore, we consider that the ambivalence and mutual in-feeding seen in this excerpt acted as recursive movements of revisiting the past (i.e., the problematic narrative) that, instead of perpetuating problems, renovated the motivation in the direction of further changes (i.e., the adoption of an innovative position and a new self-narrative).

In contrast, in Jan's case, the first reconceptualization IM appeared in Session 4; that is, in the initial phase of the psychotherapy process. Given that she had already experienced some changes in the form of a symptomatic reduction during the first four weeks of therapy, the fact that the hives came back again triggered implicit ambivalence towards the possibility of effective change. In this case, we believe that the client's ambivalence - expressed as a vague apprehension towards the meaning of the symptoms' return - was the manifestation of a fear of failure and of remaining powerless to overcome the problem despite personal efforts to change and seek therapeutic help. The fact that Jan was then able momentarily to disengage from these doubts, and adopt a meta-position towards the event, led to an interesting insight about the symptom that reframed the meaning Jan had attributed to it. Specifically, whereas before the hives could mean the problem regaining control in her life, from that moment on Jan was able to construe the possibility that the symptoms actually act as basic expressions of unattended affective and bodily needs. Consequently, this inter-subjective reframing of the symptoms' meaning promoted a renewed hope in her and encouraged her to persevere towards change.

Finally, in the third case, the first reconceptualization IM emerged in the first session, the very beginning of the psychotherapy process, in distinct contrast with the other cases. In this case, the meta-position emerged initially, with Lisa reflecting upon her role in the marriage and on how she used to react to her husband. The therapist helped her to understand how she needed to focus more on herself and her feelings. As Lisa tried to distance herself from her husband's problems in her first 
reconceptualization IM, we saw her taking the first steps to hold him accountable for his gambling habit and parenting choices. However, this initial assertive movement led to the emergence of ambivalence, appearing under the form of a self-critical voice that questioned her right to emphasize her needs, and eliciting the sense of failure as a wife giving up on her husband. In an attuned emphatic movement, Lisa's therapist sensed how poignant these negative feelings were, and acknowledged them, giving room for their expression and exploration in the therapeutic dialogue. Yet, it was the use of a powerful metaphor that resonated with Lisa's internal experience (like getting close to a brick wall) that restored the path to narrative innovation, potentiating another reconceptualization IM in the client. We consider that this challenging movement was very productive in the repositioning of Lisa back to a focus on herself and the reaffirmation of the legitimacy of her needs.

Given these cases, we may consider three different types of ambivalence: (1) mutual in-feeding, as clients doubt whether to change or remain the same (exhibited by Sarah and Lisa); (2) ambivalence related to the fear of failure in the path to change (Jan); and (3) ambivalence expressed by a meta-position, related to the difficulties triggered by changes (Sarah). Furthermore, ambivalence may appear before (Jan), after (Lisa) or during (Sarah) a reconceptualization IM, when the client adopts the meta-position. In turn, the meta-position can also appear before (Lisa) or more usually during the reconceptualization IM (Sarah and Jan). Regardless of the onset of the meta-position, all the vignettes illustrate that the differentiation and elaboration of the meta-position's perspective permitted the dissolution of ambivalence, and frequently led to further innovation (in the form of reflection or another reconceptualization IMs). This interpretation is in line with other authors' arguments for the developmental potential of a meta-position as facilitating therapeutic change (Hermans, 2001, 2003; Leiman and Stiles, 2001; Engle and Arkowitz, 2006; 2008; Gonçalves et al., 2009).

Despite the specific therapeutic interventions exhibited in these situations, we would probably benefit from a more systematic analysis of specific interventions that are more fitted to address ambivalence and transform it productively, promoting a differentiation of the metaposition and facilitating a positive evolution of the therapeutic process. Therefore, an interesting avenue of research in the future could be the pursuit of more intensive case studies and a systematic comparison of therapeutic episodes in them. This could lead to a more precise discrimination of therapeutic interventions more fitted to match certain types 


\section{PROOF}

Transforming Self-Narratives in Psychotherapy

63

of ambivalence, in order to engage the opposing voices in dialogue and to enhance self-observation skills in the client, facilitating the development of a meta-position and psychological distancing from problems.

\section{Conclusion}

In this chapter, we claimed that ambivalence is a persistent feature of the change process, acquiring multiple shapes throughout therapy evolution. Thus, therapists need to be prepared to recognizing the different forms ambivalence can materialize in dialogue - either the mutual in-feeding between problematic and innovative voices or other forms of ambivalence towards change, mainly gravitating around fear and uncertainty towards the future.

We have argued that the differentiation and development of a metaposition in the self is an important tool to deal with this ambivalence and resistance to change, though more systematic studies are needed in order to understand its development and function. This position can not only help to understand ambivalent voices in psychotherapy, acknowledging the underlying self-protective needs that this ambivalent voices can express, but also, most importantly, discover how to surpass them and to foster further changes. It is then, in the delicate balance between old and new, gradually abandoning old voices and rehearsing new ones, where new self-narratives become a possibility and self-development becomes a fact.

\section{Acknowledgements}

This chapter was supported by the Portuguese Foundation for Science and Technology (FACT), by the Grant PAD/PSI/72846/2006 (Narrative Processes in Psychotherapy, 2007-10) and by the PhD Grant SIR/ $\mathrm{BD} / 30880 / 2006$. We are very grateful to Leslie Greenberg and Lynne Angus from York University (Toronto, Canada) for allowing us the use of transcripts from the York Depression Project I.

\section{References}

Abbey, E. (2004) 'Circumventing ambivalence in identity: The importance of latent and overt aspects of symbolic meaning', Culture and Psychology 10, 331-6.

Abbey, E. and Valsiner, J. (2005) 'Emergence of meanings through ambivalence', Forum: Qualitative Social Research 6 (1), Art. 23. Available: www.qualitative research.net 


\section{PROOF}

Carla Alexandra Castro Cunha et al.

Arkowitz, H. (2002) 'Towards an integrative perspective on resistance to change', Journal of Clinical Psychology: In session 58, 219-27.

Bakhtin, M. M. (1984) Problems of Dostoevky's Poetics. Minneapolis, MN: University of Minnesota Press (original work published in 1963).

Boritz, T. Z., Angus, L., Monette, G. and Hollis-Walker, L. (2008) 'An empirical analysis of autobiographical memory specificity subtypes in brief emtionfocused and client-centered treatments of depression', Psychotherapy Research 18, 584-93.

Botella, L., Herrero, O., Pacheco, M. and Corbella, S. (2004) 'Working with narrative in psychotherapy: A relational constructivist approach'. In Angus, L. E. and McLeod, J. (Eds) The Handbook of Narrative and Psychotherapy. Thousand Oaks, CA: Sage.

Bruner, J. S. (1990) Acts of Meaning. Cambridge: Harvard University Press.

Cunha, C., Gonçalves, M. M., Valsiner, J., Mendes, I. and Ribeiro, A. (forthcoming) 'Rehearsing renewal of identity: Reconceptualization on the move'. In Bertau, M. C., Gonçalves, M. M. and Raggat, P. (Eds) The Development of the Dialogical Self. Charlotte, NC: Information Age.

Dimmagio, G. (2006) 'Changing the dialogue between self voices during psychotherapy', Journal of Psychotherapy Integration 16, 313-45.

Dimaggio, G., Salvatore, G., Azzara, C. and Catania, D. (2003) 'Rewriting selfnarratives: The therapeutic process', Journal of Constructivist Psychology 16, 155-81.

Engle, D. E. and Arkowitz, H. (2006) Ambivalence in Psychotherapy. New York: Guilford.

Engle, D. and Arkowitz, H. (2008) 'Viewing resistance as ambivalence: Integrative strategies for working with resistant ambivalence', Journal of Humanistic Psychology 48, 389-412.

Engle, D. and Holiman, M. (2002) 'A gestalt-experiential perspective on resistance', Journal of Clinical Psychology/In Session: Psychotherapy in Practice 58, 175-83.

Gonçalves, M. M. and Ribeiro, A. (in press) 'Narrative processes of innovation and stability within the dialogical self'. In Hermans, H. J. M. and Gieser, T. (Eds) Handbook of Dialogical Self. Cambridge: Cambridge University Press.

AQ3 Gonçalves, M. M. and Salgado, J. (forthcoming) 'Adult life's narratives: Stability and innovation, Insights from psychotherapy research'.

Gonçalves, M. M., Matos, M. and Santos, A. (2009) 'Narrative therapy and the nature of 'innovative moments' in the construction of change', Journal of Constructivist Psychology 22, 1-23.

Gonçalves, M. M., Mendes, I., Cruz, G., Ribeiro, A. P., Angus, L. E. and Greenberg, L. S. (submitted) 'Narrative change in client-centered and emotion-focused therapy', Psychotherapy Research.

Gonçalves, M. M., Mendes, I., Ribeiro, A., Angus, L. and Greenberg, L. (in press) 'Innovative moments and change in emotional focused therapy: The case of Lisa', Journal of Constructivist Psychology.

Gonçalves, M. M., Ribeiro, A. P., Conde, T., Matos, M., Martins, C., Santos, A. and Stiles, W. B. (in press). 'How bypassing innovative moments in psychotherapy contributes to the therapeutic failure: The role of mutual in-feeding', Psychotherapy Research.

Gonçalves, M. M., Ribeiro, A., Matos, M., Santos, A. and Mendes, I. (in press) 'The Innovative Moments Coding System: A coding procedure for tracking 


\section{PROOF}

changes in psychotherapy'. In Salvatore, S., Valsiner, J. Strout, S. and Clegg, J. (Eds) Yearbook of Idiographic Science 2009: Vol. 2. Rome: Firera Publishing Group.

Gonçalves, M. M., Santos, A., Salgado, J., Matos, M., Mendes, I., Ribeiro, A., Cunha, C. and Gonçalves, J. (2010) 'Innovations in psychotherapy: Tracking the narrative construction of change'. In Raskin, J. D., Bridges, S. K. and Neimeyer, R. (Eds) Studies in Meaning 4. New York: Pace University Press.

Gonçalves, O. F., Henriques, M. and Machado, P. P. (2004) 'Nurturing nature: Cognitive narrative strategies'. In Angus L.E. and McLeod J. (Eds) The Handbook of Narrative and Psychotherapy. London: Sage.

Gonçalves, O. F. and Machado, P. P. P. (1999) 'Narrative in psychotherapy: The emerging metaphor', Journal of Clinical Psychology 55, 1175-7.

Greenberg, L. Rice, L. and Elliott, R. (1993) Facilitating Emotional Change. New York Guilford Press.

Greenberg, L. S. and Watson, J.C. (1998) 'Experiential therapy for depression: Differential effects of client-centered relationship conditions and active experiential interventions', Journal of Psychotherapy Research 8, 210-4.

Hermans, H. J. M. (2001) 'The construction of a personal position repertoire: Method and practice', Culture and Psychology 7, 323-65.

- (2003) 'The construction and reconstruction of a dialogical self', Journal of Constructivist Psychology 16, 89-130.

Hermans, H. J. M. and Hermans-Jansen, E. (1995) Self-Narratives. New York: Guilford.

Hermans, H. J. M. and Kempen, H. (1993) The Dialogical Self. San Diego, CA: Academic Press.

Hermans, H. J. M., Kempen, H. and van Loon, R. (1992) 'The dialogical self: Beyond individualism and rationalism', American Psychologist 47, 23-33.

Honos-Webb, L., Stiles, W. B. and Greenberg, L. S. (2003) 'A method of rating assimilation in psychotherapy based on markers of change', Journal of Counseling Psychology 50, 189-98.

Honos-Webb, L., Stiles, W. B., Greenberg, L. S. and Goldman, R. (1998) 'Assimilation analysis of process-experiential psychotherapy: A comparison of two cases', Psychotherapy Research 8, 264-86.

Honos-Webb, L., Surko, M., Stiles, W. B. and Greenberg, L. S. (1999) 'Assimilation of voices in psychotherapy: The case of Jan', Journal of Counseling Psychology $46,448-60$.

Josephs, I. and Valsiner, J. (1998) 'How does autodialogue work? Miracles of meaning maintenance and circumvention strategies', Social Psychology Quarterly 61, 68-83.

Leiman, M. and Stiles, W. B. (2001) 'Dialogical sequence analysis and the zone of proximal development as conceptual enhancements to the assimilation model: The case of Jan revisited', Psychotherapy Research 11, 311-30.

Matos, M., Santos, A., Gonçalves, M. M. and Martins, C. (2009) 'Innovative moments and change in narrative therapy', Psychotherapy Research 19, 68-80.

McAdams, D. P. (1993) The Stories We Live By. New York: William Morrow.

Meira, L. M. A. (2009) Mudança narrativa: estudos sobre processos de inovação pessoal na resolução de problemas de vida [Narrative change: Study about personal innovation from daily problem-solving]. Unpublished $\mathrm{PhD}$ thesis. Braga: Universidade do Minho. 


\section{PROOF}

Mendes, I., Ribeiro, A., Angus, L., Greenberg, L. and Gonçalves, M. (in press) 'Innovative moments and change in emotion focused therapy', Psychotherapy Research.

Messer, S. (2002) 'A psychodynamic perspective on resistance in psychotherapy: Vive la résistance', Journal of Clinical Psychology: In session 58, 157-63.

Santos, A. and Gonçalves, M. M. (2009) 'Innovative moments and change processes in psychotherapy: An exercise in new methodology'. In Valsiner, J., Molenaar, P. C. M., Lyra, M. C. D. P. and Chaudhary N. (Eds) Dynamic Process Methodology in the Social and Developmental Sciences. New York: Springer.

Santos, A., Gonçalves, M. M., Matos, M. and Salvatore, S. (2009) 'Innovative moments and change pathways: A good outcome case of narrative therapy', Psychology and Psychotherapy: Theory, Research and Practice 82, 449-66.

Santos, A., Gonçalves, M. M. and Matos, M. (2010) 'Innovative moments and poor outcome in narrative therapy', Counseling and Psychotherapy Research 1, $1-11$.

Sarbin, T. R. (1986) 'The narrative and the root metaphor for psychology'. In Sarbin T. R. (Ed.) Narrative Psychology. New York: Praeger.

Stiles, W. B. (2001) 'Assimilation of problematic experiences', Psychotherapy 38, 462-5.

Valsiner, J. (2002) 'Forms of dialogical relations and semiotic autoregulation within the self', Theory and Psychology 12, 251-65.

White, M. and Epston, D. (1990) Narrative Means to Therapeutic Ends. New York: Norton.

Zittoun, T. (2007) 'Dynamics of interiority: Ruptures and transitions in the self development'. In Simão, L. and Valsiner, J. (Eds) Otherness in Question. Greenwich, CT: InfoAge. 